\title{
Seminiferous Epithelium of Rats with Food Restriction and Carbon Tetrachloride-Induced Cirrhosis
}

\author{
Marilise M. Horn, Ana R. Ramos, Leonardo Winkelmann, Ursula S. Matte, Helena A. \\ Goldani, Themis R. Silveira
}

Gene Therapy Center (MMH, USM), and Experimental Hepatology Laboratory (ARR, LW, HAG, TRS), General Hospital of Porto Alegre, Federal University of Rio Grande do Sul, Porto Alegre, Brazil

\begin{abstract}
Objective: Analyze the changes in the seminiferous epithelium in rats with carbon tetrachloride-induced cirrhosis $\left(\mathrm{CCl}_{4}\right)$. Materials and Methods: Forty-eight male Wistar rats aged 45-50 days, weighing 150-180 grams were used. Twenty-two rats underwent $\mathrm{CCl}_{4}$-induced cirrhosis with $\mathrm{CCl}_{4} 0.25 \mathrm{~mL} / \mathrm{Kg}$ weekly intragastrically once a week, during 10 weeks. Additionally, they had a 44\% food restriction diet (Group 1). The control group was divided in two subgroups: 13 rats had a $44 \%$ food restriction diet and no $\mathrm{CCl}_{4}$ (Group 2) and 10 rats were not submitted to $\mathrm{CCl}_{4}$ or food restriction (Group 3). After 10 weeks, the rats were sacrificed and liver sections were collected for histological analysis. The testicular analysis was carried out to evaluate the frequency of tubules in stages VIII and XIV.

Results: The mean rates of stage VIII in animals with food restriction plus $\mathrm{CCl}_{4}$-induced cirrhosis and food restriction without $\mathrm{CCl}_{4}$ were significantly different from animals without either food restriction or $\mathrm{CCl}_{4}(18.1 \pm 5.5 \%, 20.5 \pm 2.5 \%$ and $13.4 \pm 3.5 \%$, respectively, $\mathrm{p}=0.002$ ). The mean rate of stage VIII in rats with cirrhosis was not significantly different from rats without cirrhosis $(18.1 \pm 5.5 \%$ and $17.4 \pm 4.6 \%$ respectively). The mean frequency of stage XIV in rats with cirrhosis was significantly greater than rats without cirrhosis $(4.7 \pm 2.3 \%$ and $6.8 \pm 1.9 \%$ respectively, $\mathrm{p}=0.027)$.

Conclusion: Animals with $\mathrm{CCl}_{4}$-induced cirrhosis and food restriction have shown alterations in spermatogenic cycle that were not seen in rats without $\mathrm{CCl}_{4}$-induced cirrhosis and food restriction.
\end{abstract}

Key words: rats; liver cirrhosis, experimental; carbon tetrachloride; food deprivation; spermatogenesis

Int Braz J Urol. 2006; 32: 94-9

\section{INTRODUCTION}

The presence of hypogonadism in cirrhosis was first described in 1966 (1); however, its pathogenesis has not yet been well established. Some cytokines of anabolic function in the testicles, such as IGF-I (Insulin-like growth factor-I) are reduced in cirrhotic rats. This cytokine reduces the effects of cirrhosis in the testicle (2).

The gonadal dysfunction is common in chronic liver diseases, but most of the studies have been done in patients with cirrhosis induced by alcohol (3). Some studies have sought the explanation for the relationship between cirrhosis and hypogonadism. Patients with cirrhosis presented higher serum levels of 17 beta-estradiol and prolactin and lower FSH than controls (4). Hypogonadism has been correlated to the level of liver damage in cirrhosis caused by chronic hepatitis (5). On the other hand, it has been demonstrated that energy-restricted diet is responsible for deleterious effects on reproduction more than protein-restricted diet in rats (6). It is unclear if cirrhotic 
patients could present any spermatogenesis dysfunction induced not only by liver disease but also induced by malnutrition secondary to liver disorder.

Spermatogenesis presents three important phases: a) proliferative phase (spermatogonia), in which cells undergo rapid successive divisions; b) meiotic phase (spermatocytes) in which genetic material is recombined and segregated; and c) differentiation or spermiogenic phase (spermatids) in which spermatids transform into specialized cells able to fertilize (7). The stages of spermatogenesis can be divided by morphological criteria into various development steps, based on the form and shape of the acrosome and the cells of a cell association (8).

The morphological features of the seminiferous epithelium in cirrhotic rats and restricted diet intake have not yet been described. Thus, the present study aimed to check, by means of the histological analysis of the testicles, the possible changes in the seminiferous epithelium in rats with cirrhosis induced by Carbon Tetrachloride $\left(\mathrm{CCl}_{4}\right)$ and food restriction.

\section{MATERIALS AND METHODS}

The study was conducted according to the guidelines for animal research (Guide for the Care and Use of Laboratory Animals) (9), and was approved by the Hospital Research Ethics Committee.

During a quarantine period of observation, the animals received a standard rat chow (Nuvilab CR-1 ${ }^{\circledR}$, Nuvital S.A., Colombo - PR, Brazil), based on recommendations from the National Research Council and National Institute of Health - USA - providing $290 \mathrm{KcaL} / 100 \mathrm{~g}$, which composition was $22 \%$ protein, $4 \%$ fat and $4 \%$ crude fiber. Based on our previous data, the ad libitum food intake was established as $22 \mathrm{~g} / \mathrm{rat} /$ day. In order to have $\mathrm{CCl}_{4}$ full toxicity (10), a $44 \%$ food restriction intake (12 grams/rat/day) was used.

Forty-five male Wistar rats aged 45-50 days and weighing $150-180 \mathrm{~g}$ were used. The rats were kept in groups of five per cage, at a room temperature between $18-22^{\circ} \mathrm{C}$ with cycles of light-darkness of 12 hours.
Cirrhotic animals (Group 1): Twenty-two rats were used in this group. Cirrhosis was obtained by the administration of $\mathrm{CCl}_{4}$ (Merck p.a., Germany), $0.25 \mathrm{~mL} / \mathrm{kg}$, diluted in $1 \mathrm{~mL}$ of olive oil. The $\mathrm{CCl}_{4}$ was given once a week, intragastrically by gavage using a 6F polyethylene catheter for tracheal aspiration (MarkMed Ltd., São Paulo, Brazil) during 10 weeks. All rats received Phenobarbital, $350 \mathrm{mg} / \mathrm{L}$, added to the ad libitum drinking water (10).

Control animals: The main control group consisted of two subgroups. Thirteen rats (Group 2) were submitted to a $44 \%$ food restriction diet and received once a week $1 \mathrm{~mL}$ of olive oil by gavage in the same way as the animals of group 1 , treated with $\mathrm{CCl}_{4}$. The other group consisted of 10 rats that were not submitted to any kind of procedure (Group 3).

After 10 weeks, all animals were sacrificed and liver sections were stained with hematoxylineosin (HE) and Sirius red. A semi-quantitative score was adapted to categorize liver damage: $0=$ no fibrosis; $1=$ stellate enlargement of portal tract but without septa formation; 2 = enlargement of portal tract with rare septa formation; $3=$ numerous septa without cirrhosis; 4 = cirrhosis (10). The testicles were fixed in Bouin during 12 hours to be analyzed with HE stain.

Two hundred transversal sections of seminiferous tubules were analyzed in each testicle from all animals. The percentages of tubules in stage VIII (elongated spermatids that moved to the luminal aspect of the seminiferous epithelium and lined to the lumen) and stage XIV (meiotic anaphase or telophase of meiosis I, secondary spermatocytes, or any of the phases of meiosis) were checked (11).

A cell association or stage is a defined grouping of germ cell types at particular phases of development in cross-sectioned tubules (8). This classification divides the seminiferous epithelium cycle of rats in 14 stages according to changes in cell associations (stages) arranged in a logical sequence of developmental progression from spermatogonia through spermatozoa.

Before the analysis of different stages, a general evaluation of the sample slide was done searching for any cross-sectioned tubule with degeneration. This evaluation is important because tubules with 
marked degeneration usually loose their normal association cells, and were not included in the classification described above. A ratio of stage XIV/stage VIII was also calculated, as the proportion of cells in each of these stages seems to be dependent on each other.

Results were analyzed by two-way analysis of variance (ANOVA) by using SPSS version 12.0 USA. In all cases, $\mathrm{p}=0.05$ was established as statistically significant.

\section{RESULTS}

All 22 animals treated with $\mathrm{CCl}_{4}$ presented cirrhosis. The rats that were not submitted to $\mathrm{CCl}_{4}$ (with or without food restriction) did not show histological changes of the liver.

Rats without cirrhosis and food restriction (group 3) presented all tubules without degeneration. A few number of degenerated tubules was observed in both food restricted and cirrhotic animals (Table$1)$.

The majority of sections of seminiferous tubules of all animals was normal, and among them, a few number of degenerated seminiferous tubules were seen. The latter were characterized by loss of germ cells, vacuolization of germinative epithelium, interruption in meiosis, or presence of Sertoli cells only, as shown in Figure-1.

The percentages of stages VIII and XIV were analyzed in 100 non-degenerated tubules (with normal cell association) from each animal. Rats with cirrhosis presented lower number of cells in meiosis (XIV) than the group without food restriction. Animals submitted only to food restriction presented intermediate frequency of cells in meiosis (Table2). Animals with food restriction, with or without cirrhosis showed approximately the same ratio of $1: 4(0.27 \pm 0.1)$. On the other hand, rats without food restriction showed an approximate ratio of 1:2 (0.53 \pm 0.2 ).

Table 1 - Frequency of rats with cirrhosis, with and without food restriction, presenting cross-sections of degenerated seminiferous tubules.

\begin{tabular}{lccc}
\hline Groups & $\begin{array}{c}\text { N of Rats with Seminiferous } \\
\text { Tubules Degeneration }\end{array}$ & $\begin{array}{c}\text { N of Rats without Seminiferous } \\
\text { Tubules Degeneration }\end{array}$ & Total \\
\hline Group 1 & $6 / 22(27.3 \%)$ & $16 / 22(72.7 \%)$ & 22 \\
Group 2 & $2 / 13(8.7 \%)$ & $11 / 13(91.3 \%)$ & 13 \\
Group 3 & $0 / 10(0 \%)$ & $10 / 10(100 \%)$ & 10 \\
\hline
\end{tabular}

Chi-square test; $p=0.111$. Group $1=$ cirrhosis induced by $\mathrm{CCl}_{4}+44 \%$ food restriction; Group $2=44 \%$ food restriction without CCl Group 3 = without food restriction and without $\mathrm{CCl}_{4}$.

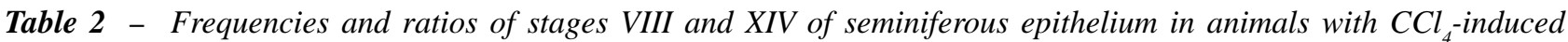
cirrhosis, food restriction and without food restriction.

\begin{tabular}{lrrrr}
\hline & Group 1 & Group 2 & Group 3 & P * \\
\hline Stage VIII & $18.1 \pm 5.5$ & $20.5 \pm 2.5$ & $13.4 \pm 3.5$ & 0.002 \\
Stage XIV & $4.7 \pm 2.3$ & $5.5 \pm 1.4$ & $6.8 \pm 1.9$ & 0.027 \\
Ratio Stage XIV / VIII & $0.27 \pm 0.1$ & $0.27 \pm 0.1$ & $0.53 \pm 0.2$ & $<0.001$ \\
\hline
\end{tabular}

$* A N O V A$ and post-hoc test; Group $1=$ cirrhosis induced by $C_{4} C_{4}+44 \%$ food restriction; Group $2=44 \%$ food restriction without CCl ; Group 3 = without food restriction and without $\mathrm{CCl}_{4}$ 


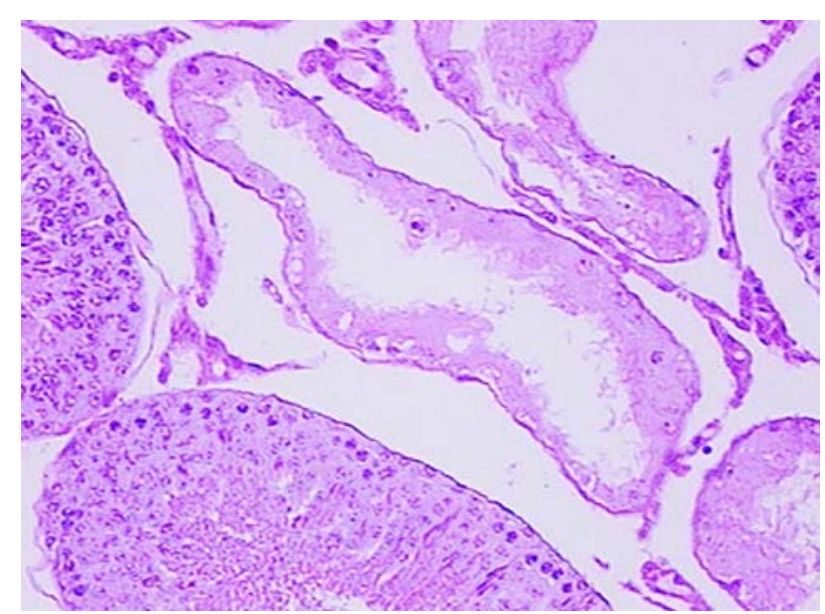

Figure 1 - Photomicrography of a transversal section of the testis, showing degenerated seminiferous tubules (HE, X 100).

\section{COMMENTS}

In this study, abnormal frequencies of stages VIII (related to liberation of elongated mature spermatids) and XIV (related to meiosis) of the spermatogenic cycle were observed in rats with food restriction $\mathrm{CCl}_{4}$-induced cirrhosis. Differences in animals submitted only to food restriction were also observed.

Changes in other features of seminiferous epithelium disorder beyond the interruption of cell division (mitosis and meiosis), such as cell degeneration and phagocytosis of germ cells, lack of maturation, and loss of germs cells. A generalized degeneration of the seminiferous epithelium was not observed, only focal alterations. These results partially agree with other studies (2), which did not find a diffused damage to the seminiferous epithelium in rats with $\mathrm{CCl}_{4}$-induced cirrhosis.

Gonadal dysfunction is common in patients with chronic liver diseases, especially in cirrhosis induced by alcohol (3). However, there is a lack of experimental studies concerning seminiferous epithelium disorders that used alcohol to induce cirrhosis.

Carbon Tetrachloride is a well-established hepatotoxic agent, which causes steatosis, necrosis and cirrhosis in animals. It has been extensively used as a model compound for inducing free radicals damage. It is bioactivated by cytochrome-P4502EI (12) into free radicals, leading to deleterious effects on liver due to lipid peroxidation (13). Carbon Tetrachloride was used in this study accordingly to previous classic experimental models of $\mathrm{CCl}_{4}$-induced cirrhosis in rats (14). Phenobarbital can enhance the toxicity of this substance (6), as its main action is to induce the secretion of cytochrome-P4502EI (15).

The magnitude of liver injury can be influenced by food restriction. It has been suggested that food restriction can aggravate the toxicity of repeated oral administration of $\mathrm{CCl}_{4}$ in rats through the enhanced metabolic activation of $\mathrm{CCl}_{4}$ by food restriction (10). Nevertheless, the effect of food restriction on $\mathrm{CCl}_{4}$ toxicity is controversial as food restriction could minimize drug-related increases in peroxidation and protect the system against drug toxicity, presumably by induction of antioxidant potential $(16,17)$. The expected effect of food restriction in this study was to induce more severe liver injury (18).

Seminiferous epithelium in rats is classified in 14 stages, and some tubules can present cellular characteristics of more than one stage. The classification of stage VIII followed the orientation of Leblond \& Clermont (11), and is characterized by the presence of elongated spermatids aligned in the lumen of the tubule to be liberated. In this study, for the animals without food restriction and without $\mathrm{CCl}_{4}$, the average frequency of stage VIII was $13.4 \pm 3.5$. For the animals with food restriction and without $\mathrm{CCl}_{4}$ it was $20.5 \pm 2.5$, and for the rats with $\mathrm{CCl}_{4}$-induced cirrhosis and food restriction, it was $18.1 \pm 5.5$. No difference was seen between the group with cirrhosis and the group with food restriction. The greater frequency of stages VIII in the animals with cirrhosis and with food restriction seems to be due to an accumulation of this stage in relation to the others. This could also be explained since stage VIII is not immediately affected by the changes in the testicular function, as cells that no longer undergo cell division characterize it. As in this study, Lue et al. (19) observed that despite the accentuated loss of germ cells, after the application of heat on the testicles of rats, the elongated spermatids were still present in most of the seminiferous tubules. Other examples can be mentioned (20), which using a model of testicular degeneration, by means of the implant of testosterone in rats, a fourfold reduction was observed in the conversion of sper- 
matogonia to spermatocyte compared to the conversion of round spermatids to elongated ones. This clearly illustrates the effect only upon germ cells in division (mitosis and meiosis).

In this study, the frequency of stage XIV (meiosis) was lower in the group with cirrhosis indicating a reduction in the cell division rate. However, this difference was also observed when animals with normal liver with and without food restriction are analyzed (Table-2). These results indicate that starving may also have an influence on the meiosis rate, since both groups with food restriction had similar results independent of cirrhosis. Another study (7) demonstrated, in rats, that diet restriction caused reduction of testicles and epididymis weight, lower testosterone levels and copulatory efficiency. Moreover, it was observed that these effects were due to energy deficiency and not by reduced protein intake. Similar results were also observed in mice (21).

In conclusion, animals with $\mathrm{CCl}_{4}$-induced cirrhosis and food restriction have shown alterations in spermatogenic cycle that were not seen in rats without $\mathrm{CCl}_{4}$-induced cirrhosis and food restriction. Other studies are needed to better clarify the real role of $\mathrm{CCl}_{4}$-toxicity and food restriction on the pathogenesis of seminiferous epithelium disorder.

\section{ACKNOWLEDGEMENT}

This work was supported by grants from the National Council for Scientific and Technological Development (CNPq - Brazil) and from the Fund for Research \& Development, General Hospital of Porto Alegre, Brazil.

\section{CONFLICT OF INTEREST}

None declared.

\section{REFERENCES}

1. Schirren C, Szarvas F, Becker K: Andrological studies in patients with chronic liver diseases. Hautarzt. 1966; 17: 175-8.
2. Castilla-Cortazar I, Diez N, Garcia-Fernandez M, Puche JE, Diez-Caballero F, Quiroga J, et al.: Hematotesticular barrier is altered from early stages of liver cirrhosis: effect of insulin-like growth factor 1. World J Gastroenterol. 2004; 10: 2529-34.

3. Van Thiel DH, Gavaler JS, Slone FL, Cobb CF, Smith WI Jr, Bron KM, et al.: Is feminization in alcoholic men due in part to portal hypertension: a rat model. Gastroenterology. 1980; 78: 81-91.

4. Mooradian AD, Shamma'a M, Salti I, Cortas N: Hypophyseal-gonadal dysfunction in men with non-alcoholic liver cirrhosis. Andrologia. 1985; 17: 72-9.

5. Gursoy S, Baskol M, Ozbakir O, Guven K, Kelestimur F, Yucesoy M: Hypothalamo-pituitary gonadal axis in men with chronic hepatitis. Hepatogastroenterology. 2004; 51: 787-90.

6. Hashimoto M, Kothary PC, Raper SE: Phenobarbital in comparison with carbon tetrachloride and phenobarbital-induced cirrhosis in rat liver regeneration. J Surg Res. 1999; 81: 164-9.

7. Santos AM, Ferraz MR, Teixeira CV, Sampaio FJ, da Fonte Ramos C: Effects of undernutrition on serum and testicular testosterone levels and sexual function in adult rats. Horm Metab Res. 2004; 36: 27-33.

8. Russel LD, Ettlin RA, Sinhahikim AP, Clegg ED: The classification and timing of spermatogenesis. In: Russel LD, Histological and histopathological evaluation of the testis. Clearwater, Cache River Press. 1990; pp. 41-58.

9. Guide for the care and use of laboratory animals, National Institutes of Health, Maryland, National Research Council/Public Health Service. 1996.

10. Seki M, Kasama K, Imai K: Effect of food restriction on hepatotoxicity of carbon tetrachloride in rats. $\mathbf{J}$ Toxicol Sci. 2000; 25: 33-40.

11. Leblond CP, Clermont Y: Spermiogenesis of rat, mouse, hamster and guinea pig as revealed by the periodic acid-fuchsin sulfurous acid technique. Am J Anat. 1952; 90: 167-215.

12. Bruckner JV, Ramanathan R, Lee KM, Muralidhara $\mathrm{S}$ : Mechanisms of circadian rhythmicity of carbon tetrachloride hepatotoxicity. J Pharmacol Exp Ther. 2002; 300: 273-81.

13. Janakat S, Al-Merie H: Optimization of the dose and route of injection, and characterisation of the time course of carbon tetrachloride-induced hepatotoxicity in the rat. J Pharmacol Toxicol Methods. 2002; 48: 41-4.

14. Proctor E, Chatamra K: High yield micronodular cirrhosis in the rat. Gastroenterology. 1982; 83: 1183-90. 
15. Recknagel RO, Glende EA Jr, Dolak JA, Waller RL: Mechanisms of carbon tetrachloride toxicity. Pharmacol Ther. 1989; 43: 139-54.

16. Ramkumar KM, Rajesh R, Anuradha CV: Food restriction attenuates blood lipid peroxidation in carbon tetrachloride-intoxicated rats. Nutrition. 2003; 19: 358-62.

17. Pavanato A, Tunon MJ, Sanchez-Campos S, Marroni CA, Llesuy S, Gonzalez-Gallego J, et al.: Effects of quercetin on liver damage in rats with carbon tetrachloride-induced cirrhosis. Dig Dis Sci. 2003; 48: 824-9.

18. Snyder R, Andrews LS: Toxic effects of solvents and vapors. In: Klaassen CD, Amdur MO, Doull J (eds), Casarett and Doull's Toxicology: The Basic Science of Poisons. New York, McGraw-Hill Companies. 1996; pp. 737-71.
19. Lue YH, Hikim AP, Swerdloff RS, Im P, Taing KS, Bui T, et al.: Single exposure to heat induces stagespecific germ cell apoptosis in rats: role of intratesticular testosterone on stage specificity. Endocrinology. 1999; 140: 1709-17.

20. Sun YT, Wreford NG, Robertson DM, de Kretser DM: Quantitative cytological studies of spermatogenesis in intact and hypophysectomized rats: identification of androgen-dependent stages. Endocrinology. 1990; 127: 1215-23.

21. Wu A, Wan F, Sun X, Liu Y: Effects of dietary restriction on growth, neurobehavior, and reproduction in developing Kunmin mice. Toxicol Sci. 2002; 70: 23844 .

\section{Correspondence address:}

Dr. Marilise Mesquita Horn

Centro de Terapia Gênica, HCPA

Rua Ramiro Barcelos, 2350

Porto Alegre, RS, 90035-903, Brazil.

Fax: +55 51 2101-8760

E-mail: mmhorn@uol.com.br

\section{EDITORIAL COMMENT}

The authors present an interesting study focusing on the evaluation, by means of histology, of the seminiferous epithelium in rats with carbon tetrachloride-induced cirrhosis.

It was observed that the animals with $\mathrm{CCl}_{4}$ induced cirrhosis and food restriction have shown alterations in the spermatogenic cycle that had not been observed in rats without $\mathrm{CCl}_{4}$-induced cirrhosis and food restriction. However, alterations in the fre- quency and ratios of meiosis stages were similar between cirrhosis and diet-restriction groups. Therefore, one may speculate that the effects seen in the seminiferous epithelium may be due to starvation rather than $\mathrm{CCl}_{4}$. An additional experimental group, i.e., $\mathrm{CCl}_{4}$-induced cirrhosis without food restriction, would be very interesting to evaluate the role of starvation on the seminiferous epithelium in rats.

Dr. Sandro C. Esteves Androfert, Center for Male Infertility Campinas, São Paulo, Brazil E-mail: s.esteves@androfert.com.br 